\title{
O sofrimento e /ou adoecimento psíquico do(a) professor(a) em um contexto de fragilização da formação humana
}

Carta de Lígia Márcia Martins ${ }^{1}$

Resumo: Nosso objetivo é destacar relações entre o sofrimento e/ ou adoecimento do(a) professores(a) e as condições objetivas de vida e de educação que empobrecem a formação humana. Para tanto, apresentamos de partida, uma breve análise da conjuntura político-econômica contemporânea, tendo em vista a identificação de elementos que subjugam o desenvolvimento psíquico, fragilizando-o. $O$ pressuposto de base desta assertiva diz respeito à natureza social do psiquismo e, nesse diapasão, conferimos destaque às consequências potencialmente adoecedoras da sociedade da mercadoria - sob a roupagem do capitalismo flexível, que mercantiliza a própria subjetividade dos indivíduos, capturando-a e descaracterizando-a, sobretudo, no que tange à classe trabalhadora.

Palavras-chave: Capitalismo Flexível; Subjetividade Humana; Educação.

\footnotetext{
${ }^{1}$ Graduada em Psicologia, mestre em Psicologia, doutora em Educação e livre docente em Psicologia da Educação. Professora do Programa de Pós-Graduação em Educação Escolar da Faculdade de Ciências e Letras da UNESP, campus de Araraquara. E-mail: ligiamar@fc.unesp.br
} 
São Carlos, 28 de julho de 2018.

\section{Prezado Marx,}

Escrever-lhe esta carta causa em mim um sentimento ambíguo, posto que, de um lado, é sempre bom tê-lo como referência e poder buscar, em teu insubstituível legado, o apoio teórico necessário ao atendimento de nossas necessidades práticas. Mas, de outro lado, o pesar é imenso ao ter que compartilhar contigo que tuas previsões mais sombrias pairam hoje sobre nós, não nos imobilizando, mas impondo desafios colossais! Por isso, peço que compreenda o teor desta correspondência como um compartilhamento, haja vista que, seguramente, o que apresento não lhe é novidade, pelo contrário, é a prova viva da correção de tuas análises sobre a ordem políticoeconômica da sociedade burguesa. Ordem essa, que tem sabido se reinventar no que tem de pior.

Ademais, devo observar ainda que embora eu destaque uma categoria profissional particular - a dos professores e professoras, $\mathrm{o}$ que acomete sobre ela a ultrapassa, abarcando igualmente outros(as) trabalhadores(as) que, conforme nos ensinaste, se empobrecem em igual medida em que enriquecem o capital (MARX, 2004). Tecidas essas considerações introdutórias, organizo as ideias aqui presentes em torno de dois pontos: o primeiro, de análise de conjuntura para localizar o fenômeno do empobrecimento da formação humana em face da reestruturação produtiva, aqui adjetivada como capitalismo flexível e, posteriormente, dedico-me aos aspectos mais específicos do sofrimento e/ou adoecimento psíquico produzido por ela.

\section{Ponto Um: em que tempos estamos vivendo...}

Para a elaboração deste item tomo como referência central estudos desenvolvidos pelo IME (Instituto Marxista de Economia / 
Faculdade de Ciências Econômicas e Empresariais da Universidade Complutense de Madrid), mais precisamente, a obra Capitalismo e Economia Mundial, de autoria de Xabier Arrizabalo Montoro (2014), por considerá-la emblematicamente representativa do que chamaria de 'retrato dos dias de atuais'! Segundo este autor, qualquer análise que se pretenda do quadro conjuntural vigente, em nível mundial, determina que nos reportemos à crise das décadas de 1970/1980, que marcou o "fim da era de ouro do capitalismo", e que impulsionou a reestruturação produtiva e o advento do chamado "capitalismo flexível". O fato é que desde essas décadas não tem havido, no âmbito da economia mundial, um crescimento significativo e sustentável.

Caro Marx, diferentemente de vermos acontecer o velho esquema caracterizador do modo de produção capitalista, qual seja crise-estabilidade-crise, tal como prescrito em suas análises, o que se verifica na economia política contemporânea é a emergência de um novo paradigma, a saber: crise - ajustes de arroxo - crise. E, não é outro senão o Fundo Monetário Internacional - F.M.I., o principal gestor da economia em praticamente todos os países do mundo - desde a Segunda Guerra mundial, exigindo a passos largos e a qualquer custo a implementação das chamadas 'políticas de ajuste'. Todavia, na esteira do que Montoro (2004) afirma, diferentemente do que possamos imaginar, tais 'ajustes' não são estratégias pontuais para responder a circunstâncias específicas, mas passam a representar a lógica interna do capitalismo flexível, dado que as tornam permanentes.

Desde a crise de 1970/1980 e avançando em direção às crises de 2007/2008, verifica-se um refluxo das condições de acumulação do capital e o alvo primeiro do ataque passa a ser a "mercadoria força de trabalho", haja vista ser o componente central das forças produtivas. E o ataque desferido incide tanto sobre o "salário direto" (pecúnia individual pelo trabalho realizado) quanto sobre o "salário indireto" (representado pelo retorno do trabalho sob a forma de serviços públicos). Sob a aparência de um enfoque político liberal ou neoliberal - cuja marca central é o questionamento do papel interventor do Estado 
na economia, o que se vê acontecer desde as últimas décadas do século XX não é bem isso, mas sim, uma forma particular de intervenção do Estado. Ou seja, a intervenção permanece, mas muda de direção, encaminhando-se para as subvenções a determinados segmentos do capital privado (em especial o financeiro) e para ações que ele requeira tendo em vista sua expansão (MONTORO, 2014).

E esse tipo de intervenção vai ocorrer em detrimento de outras mais precisamente, em detrimento do atendimento aos direitos sociais da maioria da população, a exemplo da educação, saúde, segurança, transporte, previdência social etc. Como destacado por Chauí (2001) tudo isso deixa de ser concebido como direito e passa à condição de serviços que podem ser privatizados.

As ações do Estado passam a ter dupla face: de um lado, retira investimentos para instituições públicas e de outro cria nichos de mercado a partir da retirada de direitos, a exemplo do surgimento das grandes empresas de educação, que movimentam hoje no Brasil, milhões de reais. Trocando em miúdos, Montoro (idem) destaca que as políticas de ajuste ora implementadas vão se consolidando em três grandes eixos, representados pelas privatizações, pela desregulamentação de direitos sociais (especialmente no tocante às relações entre capital e trabalho) e pela abertura da economia nacional aos monopólios e oligopólios internacionais.

Todas essas frentes têm o mesmo objetivo: ampliar os espaços de rentabilidade para a acumulação financeira - e, para tanto, instalase um processo de contrarreformas! Contrarreformas porque ao longo da história foram as lutas sociais que impuseram limites à exploração capitalista, determinando as reformas que culminaram nos direitos democráticos. Agora, pelo contrário, entra em curso um modelo político-econômico que visa impor limites ao que limitava a máxima exploração da força de trabalho (MONTORO, 2004). Tais medidas não são apenas duras, mas profundamente agressivas. E, numa sociedade de classes ainda geram resistências sociais importantíssimas. Por isso, a implementação das mesmas não é imediata, nem linear e nem 
absoluta, condicionando-se, sobretudo, a um forte investimento propagandístico para a redução das referidas resistências!

No que tange aos três eixos referidos, Montoro (idem) nos chama atenção para as seguintes questões: no âmbito das privatizações, elas deixam de ser apenas um fato jurídico de mudança de propriedade ou gestão de serviços públicos que passam a ser privados. Na verdade, o fato jurídico torna-se apenas uma estratégia para fazer valer objetivos políticos voltados, de um lado, à acumulação financeira e de outro lado, à desvalorização da força de trabalho. Esta desvalorização ocorre tanto pela via da precarização dos contratos, representada pela corrosão do salário direto e do salário indireto, quanto pela baixa qualidade das condições de trabalho, especialmente no âmbito dos serviços públicos, que passam a sobreviver à duras penas. No plano ideológico, as privatizações são apresentadas como alternativas para a suposta inoperância do Estado para gerir o bem público e também como a melhor forma de saneamento de suas contas.

Contudo, companheiro Marx, o que temos na realidade é mais uma medida de recomposição do capital privado e de exploração na relação capital-trabalho. Não por acaso as iniciativas privatizantes incidem sobre aspectos básicos ou fundamentais da vida em sociedade, a exemplo da educação, saúde, segurança etc. tendendo à liquidação de tudo que não seja rentável em curto prazo, ou por outra, tornando o que é considerado não rentável, para o Estado, em fonte de renda para o capital privado. No caso da educação - que nos interessa mais diretamente - a privatização ocorre tanto no plano direto, com a conversão de instituições de ensino em empresas, quanto indiretamente, à medida que passam a ser gerenciadas por princípios da administração privada e avaliadas pelo quesito produtividade (CHAUí, 2003).

Em relação à desregulamentação de direitos, Montoro (2014) assevera que até meados do século XVIII, quando se instalam as relações de produção capitalistas, não havia regra alguma que regulasse a relação capital-trabalho. Jornada de trabalho, descanso remunerado, 
equivalência de salário para mesmas funções, limite de idade para ingresso no mercado de trabalho, seguridade previdenciária, dentre outras questões, como você Marx, bem sabe, foram objetos de lutas históricas dos trabalhadores, fatos que os impulsionaram às organizações de classe - como sindicatos e partidos.

Foi ao longo de décadas que a classe trabalhadora exigiu reformas e conquistou direitos fundamentais, a serem regulamentados - mesmo que a contragosto, pelo Estado burguês. Sabidamente, a regulamentação desses direitos nunca foi tranquila, nunca deixou de ser um ponto de tensão, gerado por interesses de classe conflitantes. Para a classe trabalhadora e como marco civilizatório - trata-se indiscutivelmente de direito! Mas sob a ótica da burguesia, trata-se de concessão ou benefício! Sendo assim, quanto maior o refluxo da acumulação, mais a atenção empresarial se volta para o recuo das supostas concessões, e a intensidade dos ataques se mostra diretamente proporcional ao entendimento dos mesmos como obstáculos para a acumulação.

Haja vista que as regulamentações de direitos nunca foram "dadas de brinde" pela sociedade da mercadoria, sendo, sempre, objeto de luta e de conquistas da classe trabalhadora - e nela incluídos os seus intelectuais orgânicos (GRAMSCI, 1991), enfraquecê-los, bem como às suas entidades, torna-se uma exigência e uma condição para fazer valer as contrarreformas. Para tanto, nada melhor que abolir o conceito de luta de classes, que afirma a estratificação da sociedade entre, apenas, duas classes - aqueles que possuem os meios de produção e aqueles que vendem sua força de trabalho. Em relação a isso, Montoro (2014) destaca que não por acaso desponta uma nova estratégia de divisão da população a partir de lutas ou bandeiras particulares, criando-se assim, movimentos reivindicatórios pulverizados que conduzem, não raramente, à cizânia no interior da mesma classe, que cada vez mais rapidamente vem deixando de se ver como tal. Essa é, indiscutivelmente, uma tática brilhante para enfraquecer quaisquer posições reivindicatórias comuns, aptas à luta por outra ordem econômico-social. 
O terceiro aspecto vinculado à desregulamentação de direitos, em conformidade com o autor supra referido, diz respeito à internacionalização do capital. E eis o que ele nos indica: com o advento da sociedade moderna, as transações do mercado se firmaram em escala nacional, e deram origem ao Estado-nação e às relações comerciais entre eles. Essas relações, também tornadas objetos de regulamentação foram, outrora, fortemente marcadas pela política de proteção do mercado interno, e ele, um importante parâmetro na avaliação da soberania nacional. Considerando que é no bojo do Estadonação que os movimentos reivindicatórios acontecem e impulsionam o atendimento dos direitos democráticos, tem-se uma relação de condicionabilidade recíproca entre soberania e democratização - ainda que nos limites da democratização burguesa.

Ocorre que o mesmo desenvolvimento do capitalismo que exigiu a constituição de economias nacionais se ultrapassou e se encaminhou para a internacionalização sistemática da economia, na qual imperam os monopólios e oligopólios. Os Estados-nação periféricos se convertem em espaços de mercado para a constituição de uma economia mundial, que ao mesmo tempo, determina novos vínculos entre as economias nacionais à medida que as administra. A ideia de soberania nacional é profundamente alterada e passa a ser identificada pelo 'lugar' que cada mercado nacional ocupa no cenário mundial, que por seu turno, é gerido pelas grandes potências econômicas. Não por acaso, e mais que nunca, a estabilidade de um governo é medida pelo seu afinamento com as políticas internacionais, e igualmente, mais que nunca, os governos comprometidos com algum grau, ainda que mínimo, de justiça social acabam por ser aniquilados, vide os recentes fatos políticos ocorridos aqui no Brasil.

Portanto, a principal consequência da fragilização do Estadonação e de sua soberania só pode ser o comprometimento dos direitos humanos. Insurgem as medidas que visam liquidar as negociações coletivas, incrementa-se o subemprego, a "auto exploração", 
a precarização do trabalho sob a forma de subcontratos, amplia-se a jornada e o tempo de trabalho, institui-se o trabalho gratuito ou quase gratuito, e tudo isso acrescido da precariedade de seguridade social.

E, como não nos surpreende, para a operacionalização de tais medidas, a própria formação profissional passa a sofrer questionamentos que colocam em xeque a educação escolar. Entram em cena as demandas de formação do trabalhador do século XXI, que precisa ser flexível, criativo e empreendedor, sobretudo para, se necessário, saber "auto explorar-se"! Ocorre, assim, o acirramento da lógica de preparação da mão de obra para o mercado no limite mínimo para o consumo da ciência e da técnica requeridas na execução do trabalho. A produção científica e tecnológica como marco de soberania nacional sofre, como temos acompanhado, sobretudo no âmbito das pesquisas de ponta nacionais, um golpe brutal (CHAUÍ, 2003).

Caro Marx, em linhas muito gerais, mas suficientes para sua compreensão, eis em qual situação nos encontramos. É certo que, como você já afirmou, os homens fazem a sua história, mas não a fazem sob circunstâncias de suas escolhas (MARX, 2011) e, sob a atual conjuntura, o fosso entre as possibilidades materiais da humanidade e sua objetivação nas condições de vida do conjunto da população é de proporções colossais. Esta triste realidade aponta, ainda, outro saldo, representado pelo acentuado e crescente sofrimento e/ou adoecimento psíquico dos trabalhadores em geral e dentre eles, confiro um destaque especial à categoria dos(as) professores(as). Este problema merece uma atenção específica e compartilho contigo a análise que faço sobre ele.

\section{Ponto Dois: a questão do sofrimento e/ou adoecimento psíquico...}

Viver em uma sociedade complexa, permeada pelas incertezas advindas dos infindáveis "ajustes", perpetrada por mudanças rápidas e contínuas que, via de regra, sequer são compreendidas, não é tarefa 
fácil para ninguém, e torna-se uma empreitada árdua e, em muitos casos, geradora de sofrimento. Todavia, ao destacar o fenômeno 'sofrimento' psíquico, considero que não podemos fazê-lo senão, considerando-o como síntese de múltiplas relações e determinações diversas (MARX, 1983), haja vista que ele não é um dado em si mesmo, mas a confluência de inúmeras variáveis e que assume formas de manifestação e rumos diferentes.

De partida, considero importante o reconhecimento de que o sofrimento decorre do fato de sermos seres dependentes de condições externas para assegurarmos a vida (MARX, 2004). E tais condições incidem positiva ou negativamente sobre o sujeito, condicionando a tonicidade emocional da relação e da resposta a tais condições. Mas, igualmente, o sofrimento também é expressão da capacidade humana de tomada de consciência acerca do vivido, ou por outra, da capacidade para identificar e significar, inclusive, as alterações da referida tonicidade emocional. Assim compreendido, o sofrimento resulta da identificação de obstáculos - que podem ser reais ou imaginários, no atendimento das necessidades que impulsionam a ação, e será sempre proporcional às dimensões dos mesmos.

Entendo o sofrimento, então, como uma condição - não estável, não contínua e não idêntica a si mesma, que é inerente à vida humana e que, portanto, não pode ser avaliado de modo binário: como bom ou mau! Contudo, os fenômenos humanos - a vida humana, não é tão simples, de sorte que se o sofrimento "dói" - por isso não é bom, mas de outro lado, ele pode ser um recurso para o enfrentamento das situações desafiadoras e que exigem esforços adicionais - o que é bom! Por isso, penso que não podemos perder de vista que o sofrimento também é uma das determinações históricas que tem conduzido a humanidade na busca por alternativas diante de situações limitativas ou de ameaça - seja concreta ou simbólica, impulsionando inclusive a ciência, a arte, a filosofia etc.

Por certo que a vivência do sofrimento é indesejável, mas se assim não fosse não seríamos impelidos à sua superação. Por isso, não 
considero que sejamos vítimas indefesas do sofrimento - e penso que demonstrar isso às pessoas tem sido uma das tarefas mais bonitas tanto da psicologia quanto da educação. Faço esta afirmação uma vez que as defesas requeridas não nos são legadas naturalmente - elas precisam ser construídas, haja vista a formação cultural de nossa subjetividade. Sendo assim, apontado o vínculo entre sofrimento e recursos para seu enfrentamento, me encaminho para o trato dos seus desdobramentos na vida das pessoas a partir do destaque à sua dupla dimensão, na esteira do que nos ensinou Vigotsky (1995): como processo e como produto.

Apreender o sofrimento como processo demanda a identificação dos mecanismos psicofísicos que entram em ação ao longo de sua vivência e, como tal, temos os fenômenos objetivos dados pela realidade concreta bem como as reações disparadas via sistema nervoso tendo em vista a regulação e a manutenção do organismo. Igualmente, temos o universo simbólico, ou, o conjunto de significações atribuídas pela pessoa à situação que a faz sofrer.

Já na esfera do produto, nos deparamos com as formas pelas quais a tensão gerada no/pelo processo de sofrimento é administrada. E aqui reside a situação de risco, posto que dessas formas dependa o grau de manutenção do processo ou seu enfrentamento e superação. Ou por outra, se as formas desencadeiam um tratamento inoperante, o resultado será a manutenção do sofrimento, que poderá conduzir ao adoecimento. E aqui, devo fazer uma observação: foge ao meu objetivo adensar a discussão acerca do binômio saúde/doença, todavia, compartilho contigo o que advogo como saúde: entendendo que saúde e doença são polos opostos interiores um ao outro e em permanente e contínua tensão, tomo por saúde a capacidade de enfrentamento do sistema psicofísico mantenedor da vida contra o seu oposto, que é a doença!

Por isso, considero importante destacar a diferença entre sofrimento e adoecimento. Não tenho dúvidas que todos nós, e não apenas os professores, estamos vivendo tempos de muito sofrimento 
- o que não é sinônimo de estarmos todos adoecidos! Se por um lado isto é positivo, por outro demanda atenção aos recursos e às formas pelas quais estamos enfrentando a situação. Considero que a atenção às formas pelas quais os professores vêm lidando com seus sofrimentos representa, hoje, um dos maiores desafios da psicologia da educação. Em suma Marx, a meu juízo, o sofrimento psíquico desponta como uma maneira particular de relação do sujeito com as condições objetivas dadas à sua atividade; condições estas avaliadas como ameaçadoras, imprevisíveis, incontroláveis ou ainda que exijam da pessoa mais que suas capacidades de enfrentamento.

Quando temos em causa o 'sofrimento psíquico do(a) professor(a)' estamos diante de um enfoque que vincula sofrimento e trabalho, ou, sofrimento e a natureza do trabalho realizado. Conforme afirmastes reiteradas vezes, o trabalho, para além de ser o modo ou meio pelo qual atendemos nossas necessidades é, também, um traço identitário e condição de desenvolvimento de capacidades, por isso configura a autoimagem e o próprio sentimento de pertença social. Ademais, como postulado pela psicologia histórico-cultural, não podemos deixar de reconhecê-lo como fator estruturante do psiquismo.

Conforme já apontei, a virada do século XX para o século XXI marca transformações brutais no mundo do trabalho - acirrando uma conjuntura de fortíssimos impactos sobre a subjetividade dos indivíduos, e particularmente, sobre a nossa subjetividade como professores. Dentre as consequências, destaco, em primeiro lugar, a falta de certezas em relação às finalidades do trabalho docente - que identifico com a corrosão da dimensão teleológica do trabalho. Ora, se por definição o trabalho é uma atividade teleológica, qual telos orienta hoje o trabalho do(a) professor(a)? E mais, numa sociedade que a tudo mercantiliza e que torna cada vez mais brutal a exploração da força de trabalho, quais são os motivos que sustentam hoje o 'ser professor(a)'?

Julgo que estas duas interrogações são fulcrais na análise do sofrimento do professor e, arrisco dizer, os motivos do trabalho docente - voltados à humanização dos indivíduos, que relacionam a 
educação escolar a um ideal maior de desenvolvimento das pessoas, cedem lugar, a passos largos, às finalidades pontuais e pragmáticas requeridas à sociabilidade adaptativa, tanto dos professores quanto dos alunos. E com fundamento em Leontiev (1978) eu tenho dito: o obscurantismo dos motivos é o palco para o 'sem sentido' da vida!

Em segundo lugar, coloco em relevo a perda de controle por parte do professor(a) sobre o seu próprio trabalho que, diga-se de passagem, está cada vez mais acentuada. Sob a égide da mercantilização também da educação, as instituições de ensino encontram-se cada vez mais subjugadas aos modelos de gestão empresarial e aos parâmetros de avaliação externa, que centram o olhar no produto com o mais absoluto descaso em relação ao processo e às condições objetivas nas quais ele ocorre, notadamente no que tange ao salário do docente.

'Para que fazer', 'o que fazer', 'como'e 'em quais condições' tornam-se variáveis alheias ao(à) professor(a), convertido(a) em executor(a): de metas que muitas vezes não lhe são claras; de sistemas pedagógicos apostilados, sobretudo para a educação básica; de currículos e planos de ensino - especialmente no ensino superior privado, pré-definidos e engessados, e tudo isso somado a uma burocratização desmedida.

Nessas condições, como já analisei (MARTINS, 2014) o professor é convertido num "duplo de si mesmo", numa máscara destinada a desempenhar papéis que as circunstâncias externas exigem! E essa máscara, pouco a pouco ocupa seus gestos, suas reações, seus pensamentos e sentimentos, gerando a muda resignação e 0 conformismo ou a '(des)acomodação' interna expressa em diferentes formas de sofrimento.

O terceiro fator que destaco refere-se à individualização de responsabilidade, ou seja, o(a) professor(a) se torna o(a) responsável pelo sucesso ou fracasso daquilo que realiza. E nessa direção aflora o individualismo, o autocentramento e, muitas vezes, um alheamento em relação ao outro. Ora, se por definição o trabalho pedagógico é trabalho coletivo - por mais tautológico que isso possa parecer, como realizálo num contexto que corroe a coletividade, tanto do ponto de vista 
subjetivo (individualismo) - que no mínimo fragiliza o sentimento de pertença grupal, quanto do ponto de vista objetivo - a exemplo da escassez de tempo coletivo para se dedicar ao que realmente importa para o trabalho pedagógico haja vista que as questões acessórias passam a ocupar o lugar do que é essencial; a atuação dos(as) professores(as) em várias escolas; a instabilidade de quadro gerada pela rotatividade contínua etc.

O quarto e último fator refere-se à precariedade das condições de trabalho, que atravessam desde a desvalorização salarial pela natureza do trabalho realizado - somada às sucessivas perdas que estamos acumulando nos últimos anos, que forçam o(a) trabalhador(a) professor(a) à ampliação de contratos até o seu limite máximo, num processo de expansão e invasão da jornada de trabalho para as outras esferas da vida pessoal, de sorte que, como diria Sève (1979), ele(ela) passa a viver para trabalhar, e não o seu contrário! E a isso tudo, ainda posso acrescentar outros fatores tais como: salas de aula superlotadas, insuficiência ou precariedade de insumos requeridos ao trabalho pedagógico; escolas com infraestrutura física comprometidas e muitas vezes, insalubres, dentre outras.

Em suma, o que estamos acompanhando nas atuais conjunturas é o mais absoluto descaso em relação à natureza concreta do ser humano, a ter como consequência o acirramento de contradições no âmbito do trabalho. E, ao se perder de vista a natureza concreta do indivíduo - como alguém que se torna humano por apropriação da cultura e, por conseguinte, pela via dos processos educativos, perdese também de vista a natureza concreta da educação, a quem resta a tarefa de instruir para adaptar, preparando a 'inteligência' para resolver problemas imediatos de uma realidade crucificante e, assim, limitando a educação escolar a uma frágil formação, marcada por relações superficiais e pragmáticas com os conteúdos de ensino.

É certo, como nos ensinou Adorno (2000, p. 143), que a educação será impotente se desconsiderar a tarefa de preparar as pessoas para o que está ai; porém, ela será igualmente questionável se ficar 
nisso - produzindo nada além de pessoas bem ajustadas, e o autor completa: "em consequência do que a situação se impõe precisamente no que tem de pior". E é neste âmbito que estabeleço uma relação entre o que denomino semi-profissionalização docente - advinda, sobretudo, da generalização da forma mercadoria para a esfera da educação com o sofrimento do(a) professor(a).

Não tenho dúvidas de que este projeto de semi-profissionalização incide de formas distintas sobre os(as) professores(as) da educação básica ou do ensino superior - quer nas instituições estatais ou privadas. Todavia, considero que o 'núcleo duro' deste projeto é o mesmo, qual seja: hegemonia de ideários pedagógicos desprovidos de conteúdos que corroborem análise critica da realidade - reforçando posturas adaptativas e de 'ajustamento' às políticas educacionais impostas pelos organismos multilaterais, e que retroalimentam continuamente a própria desqualificação da escola como lócus privilegiado para a formação humana.

Com isso, temos um acentuado declínio das capacidades psíquicas fundamentais requeridas à inteligibilidade do real, a exemplo da memória histórica, da atenção concentrada, do pensamento metódico, abrangente e crítico, e esse declínio sustenta vínculos cada vez mais artificiais entre indivíduo e gênero humano, bem como acerca da relação escola-sociedade. Assim, Marx, o que chamo de semi-profissionalização docente não se refere simplesmente a uma "formação a meia", mas a um modelo de formação obscurantista. E esta formação não dá conta da complexidade do objeto da educação escolar.

Este obscurantismo, terreno propício para consciências obnubiladas, aprisiona os sujeitos a um trato com os fenômenos que em pouco ultrapassa seus aspectos aparentes e periféricos, e a este nível, dificilmente compreende-se não apenas a natureza do trabalho pedagógico, mas também as condições sociais nas quais ele se realiza. Ora, como nos ensina a psicologia, a incompreensão daquilo que deveríamos compreender para agirmos eficazmente é fonte geradora 
de ansiedade e sofrimento. Não compreender, faz sofrer! Entendo, portanto, que esse tipo de profissionalização usurpa dos indivíduos as "ferramentas", os "instrumentos" psíquicos, como diria Vigotsky (1997), necessários ao enfrentamento dos inúmeros obstáculos que assolam a educação escolar. Julgo que os professores estão cada vez mais "(des)instrumentalizados" para o exercício da docência.

A característica central da educação escolar, em todos os seus níveis, aponta na direção da humanização dos indivíduos pela mediação do ensino, isto é, da apropriação das objetivações humanogenéricas mais desenvolvidas. Sendo assim, compete-lhe qualificar a relação indivíduo-conhecimento-realidade, haja vista que esta relação representa o lastro da formação da consciência. Por conseguinte, nossa luta contra o sofrimento do(a) professor(a) não deixa de ser, também, uma luta contra a desqualificação do ensino dos conhecimentos clássicos, historicamente sistematizados e referendados pela prática social da humanidade (SAVIANI, 2003), posto que tais conhecimentos são imprescindíveis à formação de sua consciência.

Entendo ainda, que essa desqualificação não se limita à falta de domínio em relação ao que ele(a) professor(a) deva ensinar, mas avança em direção ao empobrecimento da subjetividade, ao acirramento do individualismo e da competição, representado por pessoas que tem a si mesmo como alfa e ômega de seu trabalho, e da própria vida. Não quero dizer com isso que todos os professores, subsumidos a esse tipo de formação, sofram. Mas não tenho dúvidas: os que supostamente não sofrem, muitas vezes são os que fazem sofrer!

Enfim, Marx, finalizo esta correspondência com duas considerações. Avalio que o enfrentamento do sofrimento do(a) professor(a) demanda um forte investimento na formação para a resistência: resistência contra o 'sem sentido' do trabalho docente, resistência contra a certificação massificada; resistência contra a quebra de direitos democráticos e, acima de tudo, resistência contra a conversão das instituições escolares em instituições destinadas à execução acrítica de políticas limitadas aos interesses do Estado burguês. Se tais desafios 
só poderão ser enfrentados coletivamente, existe outro desafio, e esse sim, sob responsabilidade de cada professor(a) em particular: resistir à destruição dos mecanismos coletivos de luta!

A segunda consideração apela que a psicologia, como ciência e profissão, recorra à sua memória histórica, e explico: o período pós Segunda-Guerra Mundial, numa Europa assolada pelas sequelas do conflito, numa intensa crise política, social e econômica, despontou como um tempo de profundo sofrimento entre as pessoas que, talvez mais que nunca, tenham questionado a capacidade humana para resolver racionalmente as contradições da sociedade. Foi o tempo inaugural de se viver à sombra da possibilidade, tornada real, de que tudo poderia ruir, numa fração de segundos, como escombros de bombas nucleares. Naquele momento a psicologia também se colocou em xeque - num processo de avaliação dos limites e possibilidades de suas matrizes teóricas para o enfrentamento das dores e dos dilemas humanos. Penso que mais uma vez, precisamos confrontar as matrizes teóricas da psicologia burguesa à realidade mais ampla, num questionamento radical acerca de quais tem sido e quais ainda podem ser os seus contributos concretos na luta contra a barbárie.

Com as minhas saudações!

Lígia Márcia 


\section{Referências bibliográficas}

ADORNO, Theodor W. Educação e emancipação. São Paulo: Paz e Terra, 2000.

CHAUÍ, Marilena. Escritos sobre a universidade. São Paulo: Editora da UNESP, 2001.

CHAUÍ, Marilena. A universidade pública sob nova perspectiva. Revista Brasileira de Educação, n. 24, p.5-15, set/dez, 2003.

GRAMSCI, Antonio. Cadernos do cárcere. Rio de Janeiro: Civilização Brasileira, 1991.

LEONTIEV, Alexis Nikolaevich. Desenvolvimento do psiquismo. Lisboa: Livros Horizonte, 1978.

MARX, Karl. Manuscritos econômico-filosóficos. São Paulo: Boitempo, 2004.

MARX, Karl. Grundrisse: manuscritos econômicos de 1857-1858: esboços da crítica da economia política. São Paulo: Boitempo, 2011.

MARX, Karl. O capital: crítica da economia política. São Paulo: Abril Cultural, 1983.

MARTINS, Lígia Márcia. A formação social da personalidade do professor: um enfoque vigotskiano. $2^{\circ}$ ed. Campinas: Autores associados, 2014.

MONTORO, Xabier Arrizabalo. Capitalismo yeconomia mundial. Madrid: Instituto Marxista de Economia - IME, 2014. 
SAVIANI, Dermeval. Pedagogia histórico-crítica: primeiras aproximações. Campinas: Autores Associados, 2003.

SÈVE, Lucien. Marxismo e a teoria da personalidade. Lisboa: Horizonte Universitário, vol. 2, 1979.

VIGOTSKY, Lev Semionovich. Obras escogidas. Tomo III. Madrid: Visor, 1995.

VIGOTSKY, Lev Semionovich. Obras escogidas. Tomo I. Madrid: Visor, 1997. 